\title{
Lettres d'Odessa du duc de Richelieu (1803-1814), éditées par Elena Polevchtchikova et Dominique Triaire
}

\section{Victoire Feuillebois}

\section{(2) OpenEdition Journals \\ Édition électronique \\ URL : http://journals.openedition.org/studifrancesi/1366 \\ DOI : 10.4000/studifrancesi. 1366 \\ ISSN : 2421-5856 \\ Éditeur \\ Rosenberg \& Sellier}

\section{Édition imprimée}

Date de publication : 1 décembre 2015

Pagination : 599-600

ISSN : 0039-2944

\section{Référence électronique}

Victoire Feuillebois, "Lettres d'Odessa du duc de Richelieu (1803-1814), éditées par Elena

Polevchtchikova et Dominique Triaire », Studi Francesi [En ligne], 177 (LIX | III) | 2015, mis en ligne le 01 décembre 2015, consulté le 06 janvier 2021. URL : http://journals.openedition.org/studifrancesi/1366 ; DOI : https://doi.org/10.4000/studifrancesi. 1366

Ce document a été généré automatiquement le 6 janvier 2021.

\section{cc) (†) $\odot$}

Studi Francesi è distribuita con Licenza Creative Commons Attribuzione - Non commerciale - Non opere derivate 4.0 Internazionale. 


\title{
Lettres d'Odessa du duc de Richelieu (1803-1814), éditées par Elena Polevchtchikova et Dominique Triaire
}

\author{
Victoire Feuillebois
}

\section{RÉFÉRENCE}

Lettres d'Odessa du duc de Richelieu (1803-1814), éditées par Elena POLEvchTchiкоVA et Dominique TRIAIRE, Ferney, Centre International d'Étude du XVIII ${ }^{e}$ siècle, «Archives de l'Est», 2014, pp. 304.

2014

Rochechouart, Richelieu, Rastignac: on ignore souvent que ces noms de légende ont résonné au début du xix ${ }^{e}$ siècle bien loin de France, sur les bords de la mer Noire, dans une province que l'on appelait à cette époque la «Nouvelle Russie» et qui correspond à l'actuelle Crimée. Le héros de cette page méconnue de l'influence française en Russie est Armand-Emmanuel, duc de Richelieu (1766-1822), dont le présent ouvrage publie un choix de correspondance datant de l'époque où l'aristocrate russophile ayant servi sous les ordres de Catherine II occupe les fonctions de gouverneur d'Odessa. Cette publication permet de retracer le rôle décisif joué par les Français dans le développement de la cité: à l'arrivée de Richelieu, Odessa n'était, de l'aveu même de ses habitants, comme Apollon Skalkovski, qu'une «misérable petite ville qui assurait à peine sa survie» (p. 8); or les efforts de Richelieu, relayés par une importante colonie française, contribuent entre 1803 et 1814 à faire d'un petit port peuplé de modestes artisans le «terminus Sud» de l'Empire russe, pour reprendre la formule de Fernand Braudel (p. 9). En témoignent ces vers de mirliton de L'Odessiade d'Alphonse Chapelon, 
professeur au lycée Richelieu de la ville (p. 61): «Oui, j’aime Odessa, morbleu!/Et je conçois qu'on s'y plaise:/Odessa, par Richelieu,/Est d'origine française!».

La province que le tsar Alexandre $\mathrm{I}^{\mathrm{er}}$ confie à Richelieu en 1803 est en effet presque une terre vierge: contrée récemment conquise sur l'Empire Ottoman, elle ne dispose d'aucune administration et n'a guère de chance de rivaliser avec la ville toute proche de Kherson comme principal port de la mer Noire. Mais le monarque russe décide de valoriser ce territoire avec l'aide de Richelieu: ce dernier fait venir d'Europe occidentale de très nombreux colons qui participent au développement économique d'une ville ne disposant à l'origine d'aucune infrastructure pour les accueillir et manquant même du strict nécessaire - lorsqu'il prend son poste, le gouverneur doit luimême faire importer en urgence vingt-cinq chaises, introuvables en ville (p. 25)! Lorsque Richelieu repart, la ville est en pleine expansion, et si cosmopolite que les poteaux signalant les noms des rues sont en plusieurs langues (p.59). Richelieu contribue également à instaurer un climat très particulier à Odessa et à en faire une cité libérale: beaucoup des colons ont fui des persécutions dans leur pays et trouvent en Nouvelle Russie une réelle tolérance politique et religieuse auprès d'une joyeuse population faite de petits hobereaux occupés à prospérer et à jouir.

3 La correspondance éditée par Elena Polevchtchikova et Dominique Triaire rend justice au talent d'administration d'un Richelieu, à travers des lettres qui soulignent l'originalité de ses projets, marqués par l'influence physiocrate, et son dévouement - la mémoire locale a conservé la légende d'un Richelieu qui refuse d'abandonner la ville ravagée par une épidémie de peste, et de fait on le devine souvent atteint par les souffrances endurées par les colons et les premiers habitants. Elle contribue ainsi à entretenir l'image d'un grand serviteur de l'État, dont la statue trône encore aujourd'hui en haut des fameux escaliers d'Odessa. Par ailleurs, les nombreuses illustrations et la très riche introduction dressent un tableau vivant de la vie dans cette "perle de la mer Noire», qui à l'époque est une perle de culture française: une forte communauté marseillaise prospère dans cette atmosphère méridionale (p.10, pp. 22-23), tandis que les jardins botaniques de la ville sont transformés en petit Versailles (p. 46). Ce climat particulier constitue un moment important des échanges culturels franco-russes: Charles Nodier lui-même songe à s'installer en «Tartarie» (p.36) et on retrouve à intervalles réguliers dans l'ouvrage le jeune Pouchkine, qui fréquente à Odessa les restaurants et les salons des colons français.

Le lecteur de cet intéressant ouvrage aura malheureusement besoin d'être bilingue, dans la mesure où de nombreux termes russes utilisés par Richelieu dans sa correspondance n'ont pas été transcrits ou traduits. On ne pourra par ailleurs pas s'empêcher de remarquer que, par une ironie amère de l'actualité, l'ouvrage paru en 2014 avant l'annexion de la Crimée est déjà lui-même un objet d'histoire, puisqu'il évoque la région comme partie intégrante de l'Ukraine: de fait, en 2015, le terme «Nouvelle Russie» est réapparu, mais pour désigner un parti séparatiste de l'Est de l'Ukraine, et non l'époque heureuse de l'insouciante Odessa. 